\title{
EVENTOS MAGMÁTICOS ARQLIEANOS DE NATUREZA CÁLCIO-ALCALINA E THOLEIITICA NO QUADRILÁTERO FERRÍFERO E SUAS IMPLICAÇÕES TECTÔNICAS
}

\author{
MAURÍCIO ANTÔNIO CARNEIRO*, HANNA JORDT-EVANGELISTA** \& WILSON TEIXEIRA****
}

\begin{abstract}
TECTONIC IMPLICATIONS OF ARCHEAN CALC-ALKALIME AND THOLEITTIC MAGMATIC EVENTS IN THE QUADRILATTERO FERRIFERO, BRAZIL Mafic amphibolitic dikes cutting tonalitic rocks with little evidence of metamorphism are one of the singularities in the crusta, evolution of the Quadrilátero Ferrífero, in Minas Gerais. Petrographic, geochemical and geochronogical studies show that in the Bonfim Metamorphic Complex these rock types constitute two distinct magmatic series, one tholeiitic and the other calcalkaline. They were partially metamorphosed under the conditions of higher greenschist to lower amphibolite facies. In the calcalkaline tonalites the metamorphic reactions, which required the introduction of water, were difficulted by their massive structure. Therefore primary textures and mineralogy were mostly preserved. In the tholeitic rocks of the dikes the metamorphism was more homogeneous because the primary igneous mineralogy, rich in pyroxenes, is more sensible to hydration reactions than the mineralogy of the tonalites. The access of the needed aqueous fluids certainly was more effective to the mafic rocks because fluids tend to be concentrated in zones of crustal weakness such as dikes. We conclude that the non-penetrative metamorphic recrystallization of the two rocks series under the conditions of the higher greenschist to lower amphibolite facies, and also the preservation of early Archean $\mathrm{U} / \mathrm{Pb}$ ages in titanites of the tonalites, indicate that the studied region was not submitted to any penetrative tectonometamorphic event of higher metamorphic conditions than the lower amphibolite facies during the Proterozoic. Therefore we also conclude that the tectonometamorphic overprinting of the Transamazonian Event $(2.2 \mathrm{My})$ in the Bonfim Metamorphic Complex and probably also in the rest of the Quadrilátero Ferrífero was heterogeneous, not affecting all áreas with the same intensity.
\end{abstract}

Keywords: Amphibolite, Tonalite, Geochemistry, Geochronology, Metamorphism, Archean, Quadrilátero Ferrífero, Bonfim Metamorphic Complex

RESUMO Diques máficos anfibolitizados, intrusivos em rochas tonalíticas, estas últimas praticamente sem evidências metamórficas, constituem um dos aspectos singulares da evolução crustal arqueana do Quadrilátero Ferrífero, no Estado de Minas Gerais. Estudos petrográficos, geoquímicos e geocronológicos indicam tratar-se de duas suítes magmáticas distintas, uma tholeítica e a outra cálcio-alcalina, que foram metamorfizadas com intensidade diferente sob as condicões das fácies xisto verde alto a anfibolito baixo. Na suíte cálcio-alcalina tonalítica a transformação metamórfica foi dificultada por suas características estruturais e mineralógicas, de modo que a rocha mantém em grande parte as suas feições ígneas originais. Na suíte tholeiítica os efeitos do metamorfismo foram mais efetivos porque a sua composição mineralógica ígnea primária, rica em piroxênios, foi mais sensível às reações metamórficas de hidratação. Além disso, o metamorfismo destas rochas de dique foi mais pronunciado porque os fluidos aquosos necessários às reações mineralógicas tendem a concentrar-se em zonas de fraqueza crustal como aquelas por onde ascendeu o magma tholeiítico. Conclui-se que a recristalização metamórfica não-penetrativa das duas suítes sob as condições da fâcies xisto verde alto a anfibolito baixo, bem como a preservação de idades U-Pb neoarqueanas em titanitas dos tonalitos, indicam que a região estudada não foi submetida a qualquer evento tectonometamórfico de caráter penetrativo de fácies mais elevada do que anfibolito baixo no decorrer do Proterozóico. Portanto, a atuação do Evento Transamazônico (2,2 Ma) no Complexo Metamórfico Bonfim e, por extensão, no Quadrilátero Ferrífero, foi heterogênea, não afetando todas as áreas com a mesma intensidade.

Palavras Chaves: Anfibolito, Tonalito, Geoquímica, Geocronologia, Metamorfismo, Arqueano, Quadrilátero Ferrífero, Complexo Metamórfico Bonfim.

INTRODUÇÃo A região conhecida como Quadrilátero Ferrífero (Fig. 1) está inserida na porção centro sul do estado de Minas Gerais que, por sua vez, faz parte da porção meridional do Craton do São Francisco.

A evolução geológica da crosta siálica deste fragmento crustal está bem caracterizada no Complexo Metamórfico Bonfim (Carneiro 1992; Carneiro et al. 1996; Teixeira et al. 1996) a partir do Meso-Arqueano, quando foram geradas e/ou retrabalhadas algumas suítes gnaíssicas (Carneiro 1992, Noce 1995).

O Gnaisse Alberto Flores (Figura 3) tem uma idade mínima de $2.920 \mathrm{Ma}$ e contém, aparentemente, o registro mais antigo de uma herança siálica na região (Machado \& Carneiro 1992). Eventos de magmatismo máfíco fissural impostos à crosta siálica do Quadrilátero Ferrífero, ainda no MesoArqueano, são representados, por exemplo, pelo Anfibolito Paraopeba (Carneiro 1992). Já para o final do MesoArqueano, a crosta siálica do Quadrilátero Ferrífero foi acres- cida por eventos de magmatismo félsico, como é o caso dos gnaisses do tipo Souza Noschese (Carneiro 1992).

Embora sejam ainda parcialmente obscuras as relações tectônicas desta crosta siálica com a sequência supracrustal do Supergrupo Rio das Velhas (Dorr II 1969, Ladeira 1985; Schorscher 1982), o intervalo de variação de idades U-Pb em rochas do Supergrupo Rio das Velhas (Machado et al. 1992) coaduna-se com o intervalo de idades U-Pb da crosta siálica (Carneiro et al. 1995). Por outro lado, têm sido encontrados, nas unidades superiores do Supergrupo Rio das Velhas, seixos de rochas ígneas (Golia et al. 1996) petrográfica- e geoquimicamente semelhantes ao Tonalito Samambaia e ao Granito Brumadinho do Complexo Metamórfico Bonfim. Sendo assim, algumas das unidades litoestratigráficas da crosta siálica arqueana do Quadrilátero Ferrífero precedem, pelo menos, a sedimentação das unidades superiores do Supergrupo Rio das Velhas. Estas características, juntamente com o padrão geocronológico U-Pb, têm invocado ambientes tectônicos de natureza continental e/ou de margem ativa (Carneiro

* Departamento de Geologia, Escola de Minas, Universidade Federal de Ouro Preto. 35400-000 - Ouro Preto - MG - Brasil - e-mail: mauricio@degeo.ufop.br

** Departamento de Geologia, Escola de Minas, Universidade Federal de Ouro Preto. 35400-000 - Ouro Preto - MG - Brasil

*** Departamento de Geologia Geral, Instituto de Geociências, Universidade de São Paulo. 


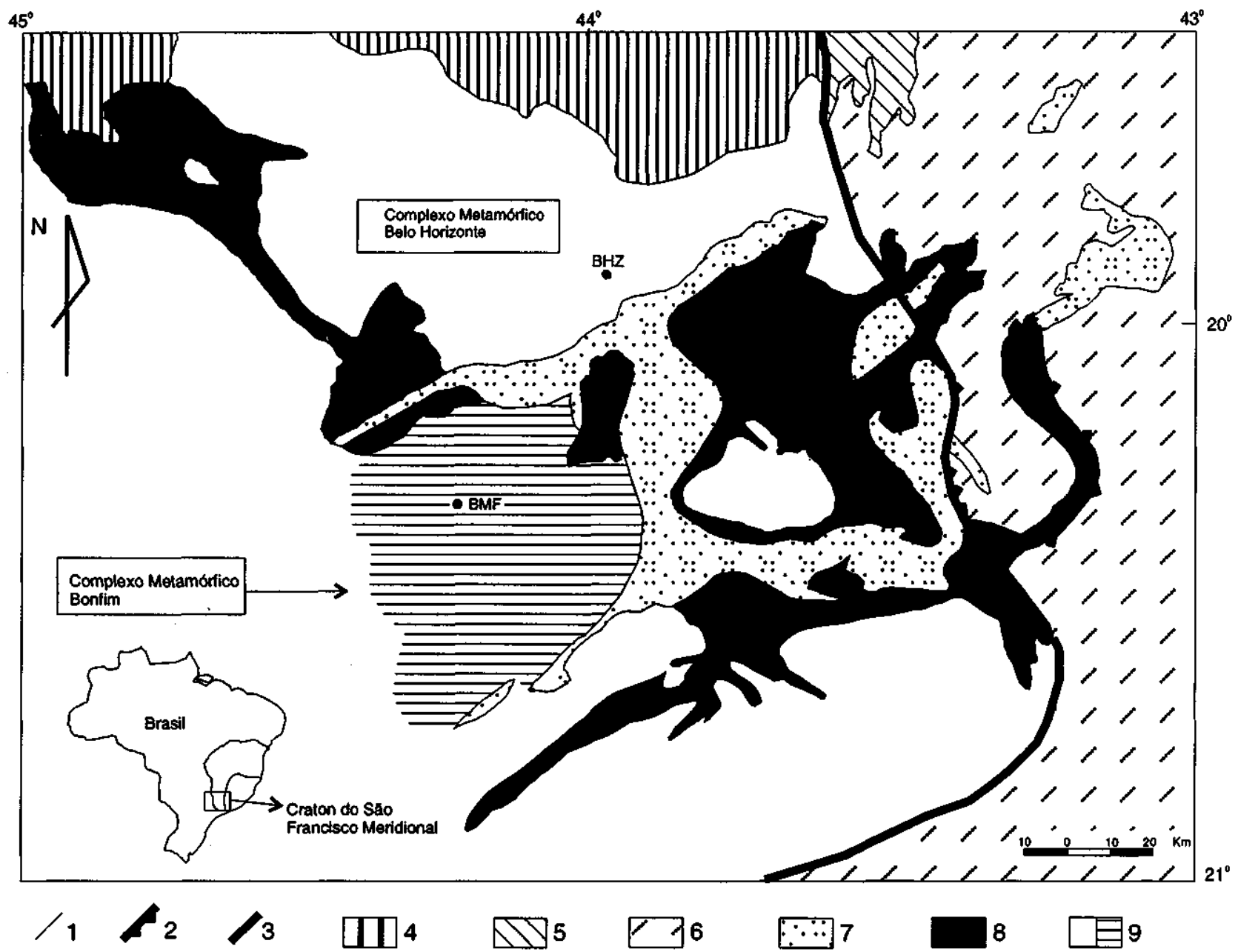

Figura 1 - Geologia do Craton do São Francisco Meridional (modificado de Carneiro J992). Simbologia: 1- Contato geológico; 2 - Empurrão; 3 - Limite cratônico oriental; 4 - Supergrupo São Francisco; 5 - Supergrupo Espinhaço; 6 - Complexo Metamórfico formado ou retrabalhado no Neo-Proterozóico; 7 - Supergrupo Minas; 8 - Supergrupo Rio das Velhas; 9 - Complexo Metamórfico Arqueano. BHZ - Belo Horizonte; BFM - Bonfim

Figure 1 - Geology of the Southern São Francisco Craton (modified after Carneiro 1992). Keys: 1 - Geológical contact; 2 - Thrust fault; 3 - Eastern cratonic boundary; 4 - São Francisco Supergroup; 5 - Espinhaço Supergroup; 6 - Metamorphic Complex formed or reworked in the Neo-Proterozoic; 7: Minas Supergroup; 8 - Rio das Velhas Supergroup; Archean Metamorphic Complex. Cities: BHZ - Belo Horizonte; BFM - Bonfim

1992) para explicar a evolução geológica deste terreno granito-greenstone, constituído, respectivamente, pela crosta siálica arquearia e o Supergrupo Rio das Velhas.

A outra unidade litoestratigráfica do Quadrilátero Ferrífero, Supergrupo Minas (Dorr II 1969), tem uma evolução estritamente relacionada ao Proterozóico (Carneiro et al. 1995 e referências ali citadas).

\section{COMPLEXO METAMÓRFICO BONFIM}

Complexo Metamórfico Bonfim (Figura 2) é, no âmbito da crosta siálica do Quadrilátero Ferrífero, um dos seus segmentos mais bem conhecidos. Este complexo é constituído, basicamente, por oito suítes, sendo que seis delas (Tabela 1), estão diretamente relacionadas ao Arqueano (Carneiro 1992, Teixeira et al. 1996).

As outras duas relacionam-se ao Proterozóico, quando novos eventos de magmatismo máfico fissural invadiram a crosta siálica arquearia. Os magmatitos destes últimos episódios têm sido designados, respectivamente, de Metadiabásio Conceição do Itaguá e Diabásio Santa Cruz (Carneiro 1992).

Todas as suítes arqueanas do Complexo Metamórfico Bonfim guardam registros isotópicos do Proterozóico obtidos pelos métodos Rb-Sr e K-Ar (Tabela 1). Estes registros, no entanto, estão relacionados a distúrbios isotópicos ocorridos sob baixas condições de temperatura e pressão, subordinados a processos tectonometamórficos de fácies xisto verde (Carneiro 1992).

Todavia, dentre as várias suítes que constituem o Complexo Metamórfico Bonfim (Carneiro 1992; Teixeira et al. 1996), destaca-se uma associação petrográfica constituída por metamafititos tholeí́ticos (Anfibolito Candeias) e granitóides cálcio-alcalinos (Tonalito Samambaia). O Tonalito Samambaia tem o seu domínio aflorante, mais significativo, no canto sudeste do Complexo Metamórfico Bonfim (Figura 2), onde esta suíte é intrusiva no Gnaisse Alberto Flores. Neste local, é possível observar matacões de tonalitos com textura hipidiomórfica preservada. Outra ocorrência do Tonalito Samambaia, embora de tamanho mais reduzido, ocorre mais ao norte, nos domínios do Gnaisse Souza Noschese (Figura 2). Já o Anfibolito Candeias aflora como diques de variada espessura, não só na porção oriental da área, onde intrudem o Tonalito Samambaia e o Gnaisse Souza Noschese, como também, em outras partes do Complexo Metamórfico Bonfim, no domínio do Gnaisse Alberto Flores (Figura 2).

As idades Sm-Nd (TDM) do Anfibolito Candeias e do Tonalito Samambaia são respectivamente 2680 e 2940 - 2800 


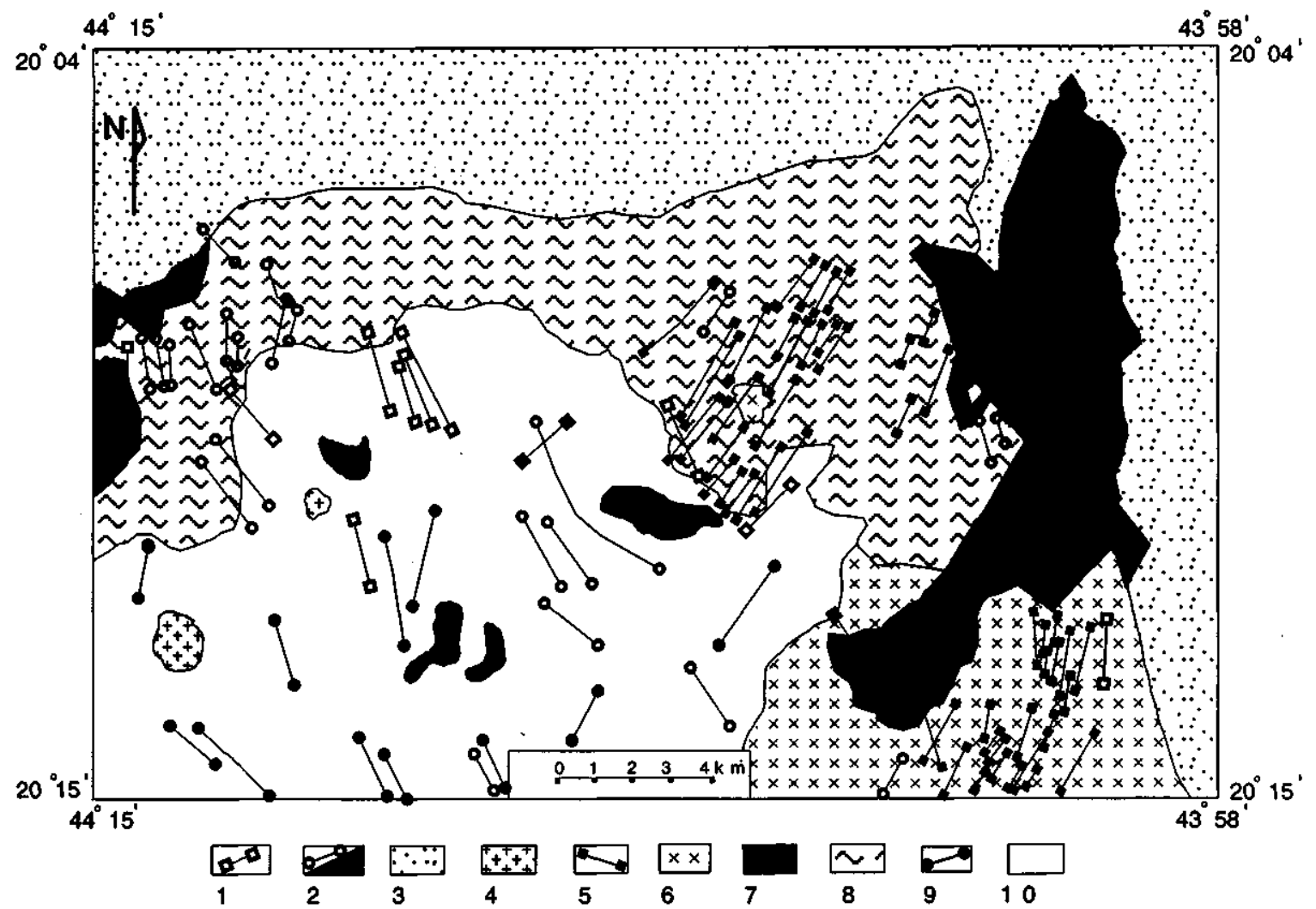

Figura 2 - Mapa geológico do Complexo Metamórfico Bonfim e de parte das sequências supracrustais do Quadrilátero Ferrifero (modificado de Carneiro 1992). Simbologia: 1 - Diabásio Santa Cruz; 2 - Metadiabásio Conceição do Itaguá; 3 - Supergrupo Minas; 4 - Granito Brumadinho; 5 - Anfibolito Candeias; 6 - Tonalito Samambaia; 7 - Supergrupo Rio das Velhas; 8 - Gnaisse Souza Noschese; 9 - Anfibolito Paraopeba; 10 - Gnaisse Alberto Flores

Figure 2 - Geologic map of the Bonfim Metamorphic Complex and part of the Quadrilátero Ferrifero supracrustal sequences (modified from Carneiro 1992). Keys: 1 - Santa Cruz Diabase; 2 - Conceição de Itaguá Metadiabase; 3 - Minas Supergroup; 4 - Brumadinho Granite; 5 - Candeias Amphibolite; 6 - Samambaia Tonalite; 7 - Rio das Velhas Supergroup; 8 - Souza Noschese Gneiss; 9 - Paraopeba Amphibolite; 10 - Alberto Flores Gneiss

Tabela 1 - Características petrográficas e geocronológicas das suítes arqueanas do Complexo Metamórfico Bonfim Table 1 - Petrographic and geochronological characteristics of the Archean Suites from the Bonfim Metamorphic Complex

\begin{tabular}{|c|c|c|c|c|c|}
\hline \multirow{2}{*}{$\begin{array}{l}\text { Suítes arqueanas } \\
\text { do Complexo } \\
\text { Metamórfico Bonfim }\end{array}$} & \multirow{2}{*}{ Caracteristicas Petrográficas Gerais } & \multicolumn{4}{|c|}{ Idade (Ma) } \\
\hline & & U-Pb ${ }^{1}$ & $\mathrm{Sm}-\mathrm{Nd}^{2}(\mathrm{TDM})$ & $\mathrm{Rb}-\mathrm{Sr}^{3}(\mathrm{WR})^{4}$ & $K \cdot A r^{3}$ \\
\hline Granito Brumadinho & $\begin{array}{l}\text { Pequenos corpos e diques cortando o bandamento } \\
\text { gnaíssico do Gnaisse Alberto Flores }\end{array}$ & $\begin{array}{c}2703+24 /-20 \\
\text { (Zircão) }\end{array}$ & $\begin{array}{c}2950 \pm 50 \\
\varepsilon(-) \text { de } 3,07 \\
2780 \pm 70 \\
\varepsilon(-) \text { de } 1,25\end{array}$ & $\begin{array}{c}982 \pm 91 \\
\mathrm{Rg}=0.741 \pm 0.002 \\
\mathrm{MSWD}=10,3\end{array}$ & $\begin{array}{l}1090-700 \\
\text { (Biotita) }\end{array}$ \\
\hline Anfibolito Candeias & $\begin{array}{l}\text { Diques máficos com blastofenocristais de plagio- } \\
\text { classio e homblenda poiquiloblástica, intrusivos nas } \\
\text { unidades anteriores, especialmente, no Tonalito } \\
\text { Samambaia }\end{array}$ & - & $\begin{array}{c}2680 \pm 58^{7} \\
\varepsilon(+) \text { de } 1,05\end{array}$ & - & $\begin{array}{l}1710 \\
\text { (Hornblenda) }\end{array}$ \\
\hline Tonalito Samambaia & $\begin{array}{l}\text { Granit6ides cinzentos com texturas Igneas preser- } \\
\text { vadas e intrusivos nos Gnaisses Souza Noschese e } \\
\text { Alberto Flores }\end{array}$ & $\begin{array}{l}2778+3 /-2 \\
\text { (Zircăo e } \\
\text { Titanita) }\end{array}$ & $\begin{array}{c}2940 \pm 80 \\
\varepsilon(-) \text { de } 2,04 \\
2800 \pm 40 \\
\varepsilon(-) \text { de } 0,31\end{array}$ & $\begin{array}{c}\mathrm{t} 188 \pm 46 \\
\mathrm{R}_{0}=0.713 \pm 0.0005 \\
\mathrm{MSWD}=24,9\end{array}$ & $\begin{array}{l}1120-720 \\
\text { (Biotita) }\end{array}$ \\
\hline Gnaisse Souza Noschese & $\begin{array}{l}\text { Otto-gnaisses graníticos cinzentos com foliação } \\
\text { milonftica bem desenvolvida, intrusivos no Gnais- } \\
\text { se Alberto Flores }\end{array}$ & - & $\begin{array}{l}3000 \pm 100 \\
\varepsilon(-) \text { de } 1,83\end{array}$ & $\begin{array}{c}1295 \pm 80 \\
R_{0}=1.006 \pm 0.017 \\
M S W D=7,9\end{array}$ & - \\
\hline Anfibolito Paraopeba & $\begin{array}{l}\text { Diques máficos boudinados e rompidos com tex- } \\
\text { tura granonematoblástica encontrados dentro do } \\
\text { Gnaisse Alberto Flores }\end{array}$ & $=$ & $\begin{array}{l}2800 \pm 102 \\
\varepsilon(-) \text { de } 0,39\end{array}$ & - & $\begin{array}{l}2160-1930 \\
\text { (Hornblenda) }\end{array}$ \\
\hline Gnaisse Alberto Flores & $\begin{array}{l}\text { Gnaisses cinzentos de composiçâo trondhjemftica. } \\
\text { Constitui a suite mais antiga do Complexo Meta- } \\
\text { morfico Bonfim }\end{array}$ & $\begin{array}{c}2772 \pm 6^{5} \\
2920^{6} \\
(\text { Zircđo) }\end{array}$ & $\begin{array}{l}2970 \pm 50 \\
\varepsilon(-) \text { de } 2,23\end{array}$ & $\begin{array}{c}2219 \pm 80 \\
\mathrm{R}_{0}=0.707 \pm 0.001 \\
\mathrm{MSWD}=2,1\end{array}$ & $\begin{array}{l}540 \\
\text { (Biotita) }\end{array}$ \\
\hline
\end{tabular}

${ }^{1}$ Machado \& Carneiro (1992); ${ }^{2}$ Teixeira et al. 1996, ${ }^{3}$ Carneiro (1992); ${ }^{4}$ Isócrona; ${ }^{5}$ Sobrecrescimento $;{ }^{6}$ Núcleo; ${ }^{7}$ Carneiro et al. (1996) 
Ma (Teixeira et al. 1996, Carneiro et al. 1996), enquanto que os zircões e titanitas do Tonalito Samambaia forneceram idades U-Pb idênticas de $2780+3 /-2$ Ma (Machado \& Carneiro 1992; Tabela 1). A concordância entre as idades U-Pb dos zircões e titanitas do Tonalito Samambaia é, por si só, um fato curioso, pois caso esta suíte tivesse sido submetida a um regime metamórfíco de fácies anfibolito, quando do metamorfismo, por exemplo, do Anfibolito Candeias, as titanitas teriam sido reequilibradas isotopicamente e estariam fornecendo a idade deste reequilíbrio. Isto, no entanto, não aconteceu pois, além de guardarem a idade de sua cristalização magmática, no sistema isotópico U-Pb das titanitas, estas rochas tem um caráter textural tipicamente magmático com a presença, inclusive, de plagioclásios com habitus euédrico a subédrico. Em contraposição a isto, o Anfibolito Candeias apresenta um caráter textural/mineralógico tipicamente metamórfico. Como estas duas unidades estão inseridas num fragmento crustal de longa atividade geológica, supostamente afetada pelos processos tectono-termais do Evento Transamazônico, a compreensão dos processos responsáveis pelo metamorfismo do Anfibolito Candeias passa a ter uma importância significativa na história tectono-metamórfica do Complexo Metamórfíco Bonfim e, por extensão, do Quadrilátero Ferrífero.

Tonalito Samambaia O Tonalito Samambaia é uma suíte de rochas leucocráticas de cor cinza a cinza escura, faneríticas, equigranulares, de granulação média a grossa. A sua composição química é essencialmente tonalítica. De maneira geral a textura é tipicamente hipidiomórfica. Ela está caracterizada por cristais subédricos a anédricos e, mais raramente, euédricos de plagioclásio e cristais anédricos de microclina e quartzo. Em amostras deformadas, no entanto, esta textura hipidiomórfica pode exibir variações locais para texturas miloníticas (s.l.).

O plagioclásio é o principal constituinte em volume das rochas da suíte tonalítica e ocorre em cristais zonados e geminados Carlsbad e albita, frequentemente saussuritizados. A intensidade dessa saussuritização varia de cristal para cristal e de amostra para amostra. Nas amostras mais cisalhadas a saussuritizacão é intensa, com transformação quase completa dos plagioclásios em epídoto/clinozoisita \pm sericita. Eles mostram, ainda, inclusões de biotita castanha e, mais raramente, de quartzo globular. Alguns cristais apresentam-se antipertíticos, exibindo manchas anédricas de microclina.

A microclina é muito subordinada, perfazendo no máximo $10 \%$ em volume nestas rochas. Ela mostra cristais anédricos e muito raramente subédricos, com geminação tartan e distribuição intersticial junto com o quartzo. Apresenta-se sempre límpida. $\mathrm{O}$ quartzo é sempre anédrico intersticial e apresenta-se em mosaicos recristalizados, com extinção ondulante. A biotita e a hornblenda são os minerais varietais destas rochas. A biotita castanha é o mais frequente, perfazendo em média cerca de $10 \%$ em volume. Ela mostra agregados lamelares com transformação para clorita verde, verde pálida ou incolor, epídoto e grãos anédricos de titanita. A sua transformação secundária, no entanto, ao contrário do observado nas demais unidades litoestratigráficas do Complexo Metamórfíco Bonfim, tem, notadamente, um predomínio para a formação de epídoto incolor em detrimento à clorita. Nas amostras mais cisalhadas a biotita pode formar leitos de espessura variável e, juntamente com o epídoto granular, envolver os plagioclásios. Inclusões de agulhas de rutilo são uma feição corriqueira nestas biotitas. A hornblenda aparece em algumas amostras. Ela exibe pleocroísmo intenso amarelo pálido, verde oliva e verde azulado. Em alguns casos o volume de hornblenda suplanta o volume de biotita e pode alcançar até $10 \%$. Titanita, allanita, zircão e apatita são acessórios comuns. Contudo, o Tonalito Samambaia é geralmente pobre em minerais opacos, que mostram formas anédricas corroídas e/ou esqueletiformes associadas à biotita e/ou hornblenda. De maneira geral, estão bordejados por titanita anédrica granular. A titanita pode constituir também grandes cristais subédricos a euédricos. Allanita é um acessório frequente e mostra cristais zonados, geminados e envolvidos por epídoto incolor. Estão geralmente associados à biotita. $\mathrm{O}$ zircão mostra cristais idiomórfícos de variadas dimensões, preferencialmente associados à biotita. Não foram observados núcleos ou inclusões nos cristais de zircão. Apatita mostra cristais idiomórficos inclusos em quartzo, feldspatos ou associados a biotita. Calcita, epídoto, sericita e clorita são minerais metamórficos crescendo sobre a paragênese principal.

Anfibolito Candeias O Anfibolito Candeias é uma suíte de rochas melanocráticas, densas, faneríticas, equigranulares a inequigranulares, de granulação média, apresentando localmente fenocristais relícticos de plagioclásios. A composição química das rochas desta suíte é essencialmente basáltica. A textura varia de decussada a granonematoblástica e é comum a alternância de leitos de anfibólio e de plagioclásio, em cristais geralmente poligonizados e com junções tríplices. O anfibólio é o principal constituinte destes anfibolitos. Este mineral exibe, de maneira geral, cristais prismáticos delgados. Outras vezes são granulares xenoblásticos e poiquiloblásticos. Em algumas rochas, o pleocroísmo mais fraco (amarelo - verde amarelado - verde azulado) e o ângulo de extinção $\left(c \wedge Z \leq 17^{\circ}\right)$ leva a supor que este anfibólio é uma actinolita. Em outra rochas, porém, o pleocroísmo intenso amarelo amarronzado - verde oliva -verde azulado e o ângulo de extinção (c $\wedge Z \geq 17^{\circ}$ ) são compatíveis com uma hornblenda. Ô plagioclásio pode ocorrer em duas gerações. A mais antiga constitui fenocristais tabulares, cujo hábito é tipicamente magmático. Estes plagioclásios relícticos mostram-se intensamente saussuritizados. A geração mais jovem é constituinte da matriz, exibe cristais anédricos, zonados e geminados segundo albita e Carlsbad. Embora sejam geralmente límpidos, podem ser portadores de finos cristais de epídoto. O quartzo é muito raro e ocorre em pequenos cristais anédricos poligonais nos leitos de plagioclásio ou inclusos na hornblenda, exibindo, raramente, extinção ondulante. Relíctos intersticiais de quartzo granofírico foram herdados do protólito ígneo. Os opacos mostram cristais anédricos de aspecto esqueletiforme, bordejados por grãos de titanita que, por sua vez, podem formar compridos cordões granulares associados aos leitos de hornblenda nas amostras mais cisa-Ihadas. Apatita, em diminutos cristais euédricos, é acessório comum. Biotita, clorita, sericita, carbonato e epídoto são minerais metamórficos. Oे epídoto desenvolve-se, particularmente, sobre os plagioclásios mais antigos e, mais raramente, sobre a hornblenda, conferindo a estes minerais um aspecto pulverulento. Este aspecto pulverulento, nos plagioclásios, é intensificado pela presença de sericita que ocorre em finas palhetas geralmente associada ao epídoto. A biotita, comumente acastanhada, desenvolve-se a partir da hornblenda e, associada a ela, tem lugar a clorita.

GEOQUÍMICA Apresentam-se nas Tabelas 2 e 3 os resultados das análises químicas em rocha total do Tonalito Samambaia e Anfibolito Candeias.

Algumas das características geoquímicas destas duas suítes podem ser deduzidas a partir dos diagramas das Figuras 3 a 6.

O Tonalito Samambaia tem um caráter cálcio-alcalino em contraposição ao caracter tholeiítico do Anfibolito Candeias (Figura 3). As Figuras 3 a 5 revelam uma aparente "bimodalidade" entre estas duas suítes, pois os resultados concentramse em dois agrupamentos distintos. No diagrama álcalis versus sílica (Figura 4) as análises de amostras do Tonalito 
Tabela 2 - Composição química de amostras selecionadas do Tonalito Samambaia Table 2 - Chemical composition of selected samples of the Samambaia Tonalite

\begin{tabular}{|c|c|c|c|c|c|c|c|c|c|}
\hline $\begin{array}{c}\text { Amostras } \\
\%\end{array}$ & ML8-J & ML13-A & MM6-A & MN10-A & MN10-E & MN10-F & MN10-H & MN10-J & NK5 \\
\hline $\mathrm{SiO}_{2}$ & 68,00 & 64,00 & 63,10 & 64,10 & 65,80 & 64,40 & 64,60 & 64,80 & 67,20 \\
\hline $\mathrm{TiO}_{2}$ & 0,46 & 0,81 & 0,76 & 0,71 & 0,68 & 0,68 & 0,73 & 0,69 & 0,56 \\
\hline $\mathrm{Al}_{2} \mathrm{O}_{3}$ & 14,20 & 16,10 & 17,30 & 15,30 & 14,90 & 15,10 & 14,70 & 15,30 & 15,40 \\
\hline $\mathrm{Fe}_{2} \mathrm{O}_{3}$ & 0,58 & 2,00 & 2,30 & 0,98 & 0,54 . & 3,10 & 0,50 & 0,64 & 2,60 \\
\hline $\mathrm{FeO}$ & 2,90 & 2,90 & 2,60 & 3,80 & 4,10 & 1,90 & 4,50 & 4,10 & 1,40 \\
\hline $\mathrm{MnO}$ & 0,06 & 0,07 & 0,06 & 0,06 & 0,06 & 0,07 & 0,07 & 0,07 & 0,07 \\
\hline $\mathrm{MgO}$ & 1,70 & 1,90 & 2,00 & 2,30 & 2,00 & 2,10 & 2,40 & 1,90 & 1,50 \\
\hline $\mathrm{CaO}$ & 3,60 & 4,20 & 4,80 & 4,70 & 4,30 & 4,40 & 4,40 & 4,50 & 3,80 \\
\hline $\mathrm{Na}_{2} \mathrm{O}$ & 4,30 & 4,20 & 3,60 & 4,70 & 4,30 & 4,60 & 4,40 & 4,30 & 3,80 \\
\hline $\mathrm{K}_{2} \mathrm{O}$ & 2,70 & 1,90 & 2,00 & 2,00 & 2,10 & 2,00 & 2,10 & 2.10 & 2,10 \\
\hline $\mathrm{P}_{2} \mathrm{O}_{5}$ & 0,14 & 0,21 & 0,21 & 0,21 & 0,19 & 0,21 & 0,22 & 0,22 & 0,16 \\
\hline LOI & 1,07 & 1,55 & 1,17 & 0,80 & 0,92 & 1,21 & 1,18 & 1,02 & 1,29 \\
\hline $\begin{array}{l}\text { Total } \\
\text { (ppm) }\end{array}$ & 99,71 & 99,84 & 99,90 & 99,66 & 99,89 & 99,77 & 99,80 & 99,64 & 99,88 \\
\hline $\mathrm{Cr}$ & 18 & 68 & 68 & 32 & 28 & 26 & 32 & 30 & 68 \\
\hline $\mathbf{N i}$ & 22 & 78 & 78 & 30 & 28 & 27 & 30 & 26 & 78 \\
\hline Co & 10 & 24 & 26 & 14 & 13 & 13 & 14 & 13 & 24 \\
\hline $\mathrm{v}$ & 82 & 72 & 67 & 100 & 96 & 108 & 100 & 78 & 56 \\
\hline $\mathrm{Cu}$ & 17 & 8 & 15 & 16 & 17 & 15 & 17 & 13 & 25 \\
\hline$Z_{n}$ & 66 & 86 & 80 & 75 & 76 & 70 & 76 & 72 & 71 \\
\hline $\mathbf{R b}$ & 100 & 56 & 92 & 63 & 68 & 69 & 66 & 67 & 84 \\
\hline $\mathbf{B a}$ & 710 & 599 & 779 & 730 & 720 & 750 & 790 & 700 & 402 \\
\hline Sr & 340 & 290 & 340 & 380 & 360 & 370 & 330 & 360 & 320 \\
\hline $\mathrm{Nb}$ & 42 & 20 & 30 & 42 & 42 & 40 & 42 & 50 & 25 \\
\hline $\mathrm{Zr}$ & 380 & 400 & 470 & 480 & 620 & 520 & 620 & 600 & 340 \\
\hline$Y$ & 30 & 36 & 42 & 38 & 33 & 35 & 37 & 37 & 36 \\
\hline$s$ & 110 & 50 & 50 & 130 & 130 & 130 & 140 & 130 & 50 \\
\hline F & 700 & 590 & 540 & 900 & 900 & 700 & 1000 & 800 & 850 \\
\hline $\begin{array}{l}\mathrm{Cl} \\
(\mathrm{ppb})\end{array}$ & 20 & 39 & 73 & 110 & 110 & 120 & 130 & 130 & 20 \\
\hline La & 52,06 & - & - & $=$ & 79,78 & $=$ & $=$ & $=$ & - \\
\hline $\mathrm{Ce}$ & 113,70 & - & - & $=$ & 152,60 & $=$ & - & - & - \\
\hline Nd & 37,21 & - & - & $=$ & 58,63 & $=$ & $=$ & - & $\cdot$ \\
\hline $\mathrm{Sm}$ & 7,47 & - & - & $=$ & 12,01 & $=$ & $=$ & - & $\cdot$ \\
\hline Eu & 1,17 & - & - & $=$ & 1,79 & $=$ & - & . & - \\
\hline Gd & 4,81 & - & - & - & 7,81 & - & - & - & - \\
\hline Dy & 3,67 & - & - & - & 6,44 & - & - & - & - \\
\hline Ho & 0,75 & $=$ & - & - & 1,26 & - & - & $=$ & $=$ \\
\hline Er & 2,07 & - & - & - & 3,25 & - & - & - & - \\
\hline Yb & 1,83 & - & - & - & 2,67 & - & - & - & - \\
\hline Lu & 0,26 & - & - & - & 0,33 & - & - & - & - \\
\hline
\end{tabular}

Tabela 3 - Composição química de amostras selecionadas doAnfibolito Candeias Table 3 - Chemical composition of selected samples of the Candeias Amphibolite

\begin{tabular}{|c|c|c|c|c|c|c|c|c|}
\hline $\begin{array}{c}\text { Amostras } \\
(\%)\end{array}$ & JG1.C & JG4-A & JG4-L & JH5-A & KH3-A & KHH-L & LJ10 & ML8-C \\
\hline $\mathrm{SiO}_{2}$ & 49,00 & 50,10 & 49,40 & 50,60 & 51,30 & 49,60 & 49,20 & 51,20 \\
\hline $\mathrm{TiO}_{2}$ & 1,60 & 1,90 & 2,10 & 1,60 & 2,00 & 1,70 & 1,90 & 1,20 \\
\hline $\mathrm{Al}_{2} \mathrm{O}_{3}$ & 13,60 & 13,10 & 12,60 & 14,20 & 13,10 & 12,90 & 13,20 & 14,00 \\
\hline $\mathrm{Fe}_{2} \mathrm{O}_{3}$ & 2,90 & 3,20 & 2,10 & 1,30 & 1,50 & 2,60 & 1,20 & 1,80 \\
\hline $\mathrm{FeO}$ & 10,40 & 11,50 & 12,90 & 12,00 & 13,60 & 13,10 & 12,90 & 11,10 \\
\hline $\mathrm{MnO}$ & 0,21 & 0,23 & 0,23 & 0,19 & 0,22 & 0,25 & 0,22 & 0,19 \\
\hline $\mathrm{MgO}$ & 6,40 & 5,60 & 5,60 & 5,60 & 4,30 & 5,10 & 6,00 & 5,90 \\
\hline $\mathrm{CaO}$ & 10,70 & 10,30 & 10,70 & 10,80 & 9,90 & 10,20 & 10,60 & 11,10 \\
\hline $\mathrm{Na}_{2} \mathrm{O}$ & 2,30 & 2,50 & 2,50 & 2,00 & 2,40 & 2,70 & 2,50 & 2,10 \\
\hline $\mathrm{K}_{2} \mathrm{O}$ & 0,54 & 0,49 & 0,49 & 0,45 & 0,45 & 0,49 & 0,36 & 0,28 \\
\hline $\mathrm{P}_{2} \mathrm{O}_{3}$ & 0,16 & 0,28 & 0,21 & 0,16 & 0,19 & 0,19 & 0,21 & 0,10 \\
\hline LOI & 1,97 & 0,58 & 0,86 & 1,03 & 0,95 & 0,82 & 1,42 & 0,92 \\
\hline $\begin{array}{l}\text { Total } \\
\text { (ppm) }\end{array}$ & 99,78 & 99,78 & 99,69 & 99,93 & 99,91 & 99,65 & 99,71 & 99,89 \\
\hline $\mathrm{Cr}$ & 200 & 120 & 220 & 220 & 132 & 136 & 230 & 340 \\
\hline $\mathrm{Ni}$ & 100 & 86 & 142 & 146 & 102 & 112 & 156 & 158 \\
\hline Co & 44 & 43 & 58 & 52 & 66 & 58 & 60 & 84 \\
\hline v & 288 & 228 & 458 & 228 & 288 & 438 & 468 & 268 \\
\hline $\mathrm{Cu}$ & 103 & 75 & 66 & 100 & 94 & 81 & 113 & 88 \\
\hline $\mathbf{Z n}$ & 147 & 187 & 167 & 127 & 137 & 137 & 137 & 113 \\
\hline $\mathbf{R b}$ & 24 & 10 & 10 & 10 & 17 & 15 & 10 & 10 \\
\hline Ba & 72 & 84 & 74 & 75 & 96 & 110 & 67 & 24 \\
\hline $\mathbf{S} \boldsymbol{r}$ & 110 & 100 & 88 & 110 & 100 & 97 & 94 & 120 \\
\hline $\mathrm{Nb}$ & 20 & 20 & 52 & 20 & 20 & 36 & 58 & 20 \\
\hline $\mathrm{Zr}$ & 134 & 172 & 240 & 156 & 210 & 182 & 210 & 132 \\
\hline $\mathbf{Y}$ & 56 & 77 & 104 & 64 & 86 & 74 & 82 & 70 \\
\hline $\mathbf{S}$ & 1000 & 1000 & 1100 & 1100 & 1100 & 1300 & 1300 & 900 \\
\hline $\mathbf{F}$ & 200 & 300 & 300 & 200 & 300 & 300 & 300 & 200 \\
\hline $\begin{array}{l}\mathrm{Cl} \\
(\mathrm{ppb})\end{array}$ & 180 & 280 & 310 & 130 & 170 & 200 & 190 & 20 \\
\hline $\mathbf{L a}$ & 7,84 & $=$ & 13,75 & 9,82 & - & - & - & - \\
\hline $\mathrm{Ce}$ & 29,20 & $=$ & 41,54 & 29,26 & - & - & - & - \\
\hline Nd & 14,64 & - & 23,17 & 16,59 & - & - & - & - \\
\hline Sm & 4,11 & - & 6,87 & 4,72 & - & - & - & - \\
\hline Eu & 1.14 & - & 1,67 & 1,22 & - & - & - & $\cdot$ \\
\hline Gd & 3,22 & - & 5,58 & 3,87 & - & - & - & - \\
\hline Dy & 4,45 & $=$ & 7,37 & 5,40 & - & - & - & - \\
\hline Ho & 0,93 & " & 1,50 & 1,13 & - & - & - & - \\
\hline $\mathrm{Er}$ & 2,83 & - & 4,55 & 3,34 & - & - & - & - \\
\hline $\mathrm{Yb}$ & 2,45 & - & 4,04 & 2,89 & - & $\cdot$ & $\cdot$ & - \\
\hline Lu & 0,29 & - & 0,50 & 0,36 & $=$ & - & - & - \\
\hline
\end{tabular}




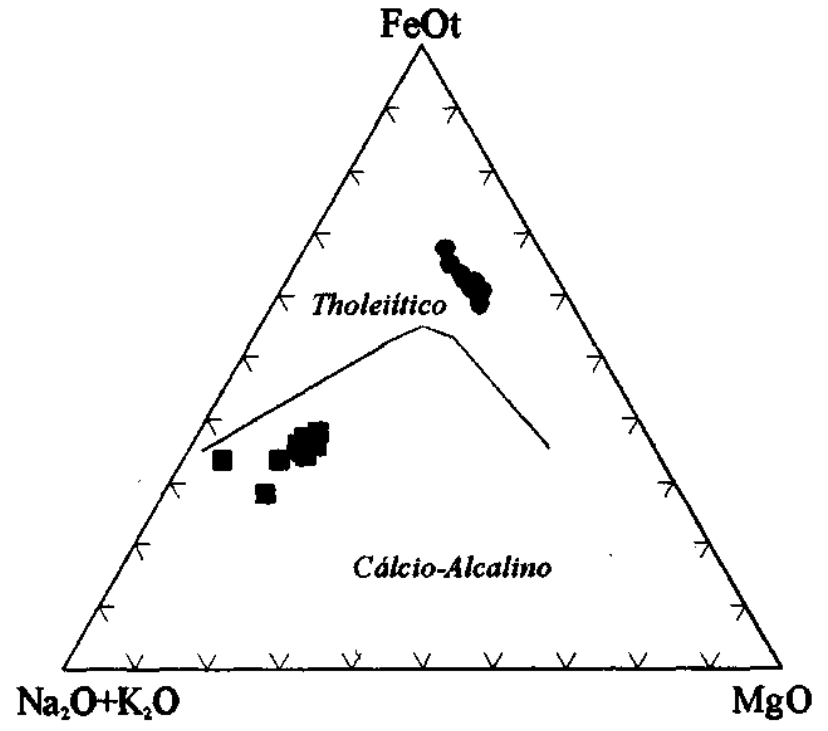

Figura 3 - Diagrama AFM (Irvine \& Baragar 1971) exibindo as composições químicas do Tonalito Samambaia (quadrados) e Anfibolito Candeias (círculos)

Figure 3 - AFM diagram (after Irvine \& Baragar 1971) for the Samambaia

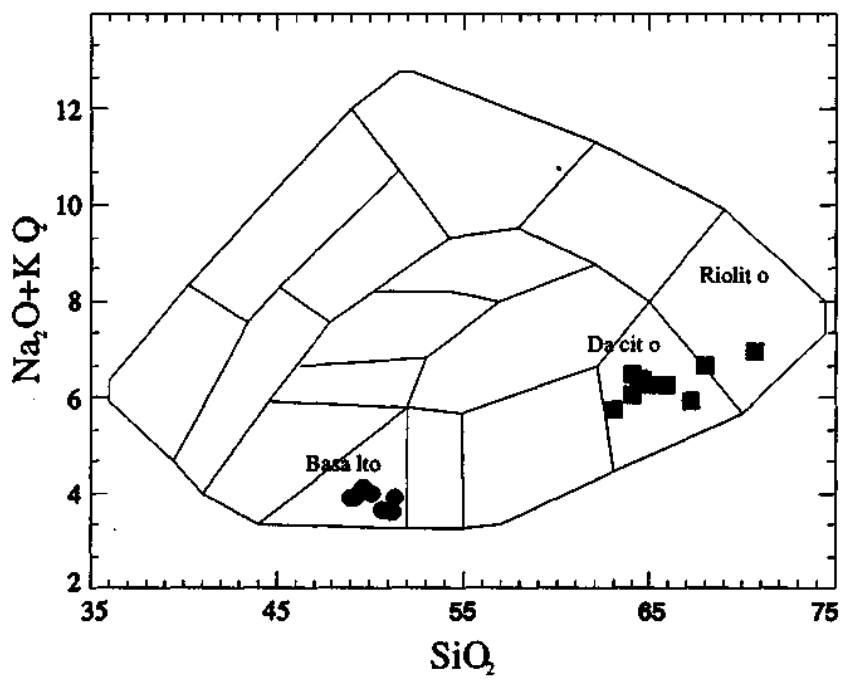

Tonalite (boxes) and Candeias Amphibolite (circles) samples

Figura 4 - Classificação do Tonalito Samambaia e Anfibolito Candeias, no diagrama álcalis versus sílica de Cox et al. (1979), onde o Tonalito Samambaia (quadrados) apresenta uma composição compativel com dacitos e riolitos e o Anfibolito Candeias (círculos) tem uma composição compativel combasaltos

Figure 4 - Chemical classification of the Samambaia Tonalite (boxes) and Candeias Amphibolite (circles) in the alkalis versus silica diagram (Cox et al 1979). The Samambaia Tonalite samples plot in the fields of dacites and rhyolites and the Candeias Amphibolite samples plot in field of basalts

Samambaia caem no campo dos dacitos e riolitos, enquanto que as amostras do Anfibolito Candeias correspondem, quimicamente, a basaltos.

Esta "bimodalidade" manifesta-se também, muito claramente, em diagramas de variação do tipo Harker (Figura 5).

Nestes diagramas verifica-se, mais uma vez que o Anfibolito Candeias e o Tonalito Samambaia constituem dois grupos quimicamente distintos. Toma-se claro, portanto, que não há tipos litológicos quimicamente intermediários entre o Tonalito Samambaia e o Anfibolito Candeias. Disto é possível concluir que se trata de dois magmatismos distintos e não de uma série magmática formada por algum processo de diferenciacão.

Finalmente, na Figura 6, é possível observar o padrão geoquímico de REE das duas suítes em estudo.

O padrão geoquímico do Tonalito Samambaia mostra-se bastante fracionado se comparado ao padrão do Anfibolito Candeias. O fracionamento é muito mais acentuado no que tange os elementos de terras raras leves. $\mathrm{O}$ padrão geoquímico do Anfibolito Candeias é mais achatado e guarda alguma semelhança com o padrão dos tholeítos arqueanos do tipo TH2deCondie(1981).

METAMORFISMO O metamorfismo de magmatitos, que são rochas compostas predominantemente por minerais anidros, requer a introdução de uma fase fluida aquosa para viabilizar as reações mineralógicas. O fluxo de fluidos através de um corpo magmático homogéneo é extremamente dificultado pela estrutura maciça e pela ausência de descontinuidades estruturais. Assim, granitóides como o Tonalito Samambaia costumam reter, na ausência de uma deformação penetrativa, a sua mineralogia e as texturas magmáticas originais. Deste modo, a principal transformação metamórfica no Tonalito Samambaia foi a saussuritização dos feldspatos. A saussuritização deu-se preferencialmente ao longo de superfícies anastomosadas e mais ou menos planares da rocha, onde também ocorreram transformações texturais como a recristalização dinâmica de biotitas e quartzo. Estas superficies, que canalizaram o fluxo dos fluidos aquosos indispensáveis às reações metamórficas, são zonas de alto strain onde se concentrou a deformação. A saussuritização de feldspatos é um a reação do tipo:

4 Ca-plagioclásio + K-feldspato $+\mathrm{H}_{2} \mathrm{O}=$ moscovita +2 zoisita +2 quartzo.

Resultados experimentais de Ackermand \& Karl (1972) indicam que a temperatura de equilíbrio desta reação é de $520 \pm 10^{\circ} \mathrm{C}$ para uma pressão de $4 \mathrm{kbar}$, que corresponde à transição da fácies xisto verde para a fácies anfíbolito. No entanto, sabe-se que a temperatura, bem como o teor de $\mathrm{Fe}^{3+}$ do epídoto e a paragênese das reações de saussuritização variam em função do quimismo do protólito e do grau de oxidação do ambiente (Braun 1974).

No Anfibolito Candeias, que ocorre sob a forma de diques, verifica-se que o metamorfismo variou de fácies xisto verde alto (paragênese actinolita + plagioclásio .+ epídoto/clinozoisita + quartzo) a anfibolito baixo (paragênese hornblenda + plagioclásio + epídoto/clinozoisita + quartzo). O metamorfismo teve, nestas rochas, uma atuação muito mais eficaz do que no tonalito, pois as transformações mineralógicas de saussuritização dos plagioclásios e de anfíbolitização dos piroxênios magmáticos foram quase que completas, restando raramente texturas ou minerais primários. Uma das razões para o fato das máficas terem sido mais homogeneamente metamorfizadas do que o tonalito está relacionada ao controle estrutural e às propriedades mecânicas das rochas que, segundo Rumble (1989), são fatores de suma importância no controle do fluxo de fluidos. As fraturas transcrustais, que são descontinuidades estruturais por onde magmas máficos ascendem através da crosta para constituir diques, tendem a focalizar o fluxo de fluidos, favorecendo as transformações metamórficas dos mafititos. $\mathrm{O}$ processo metamórfico relacionado à forte influência de fluidos aquosos e o caráter não penetrativo das transformações metamórficas também foram verificados em outros corpos ígneos do Quadrilátero Ferrífero, como é o caso do Granito Mamona (Jordt-Evangelista et al. 1993a; b). Uma outra razão para o caráter mais penetrativo das transformações metamórficas sofridas pelo Anfibolito Candeias é a composição mineralógica ígnea primária, rica em piroxênios, que são minerais mais propícios a reações metamórficas de hidratação do que os minerais máficos bio- 

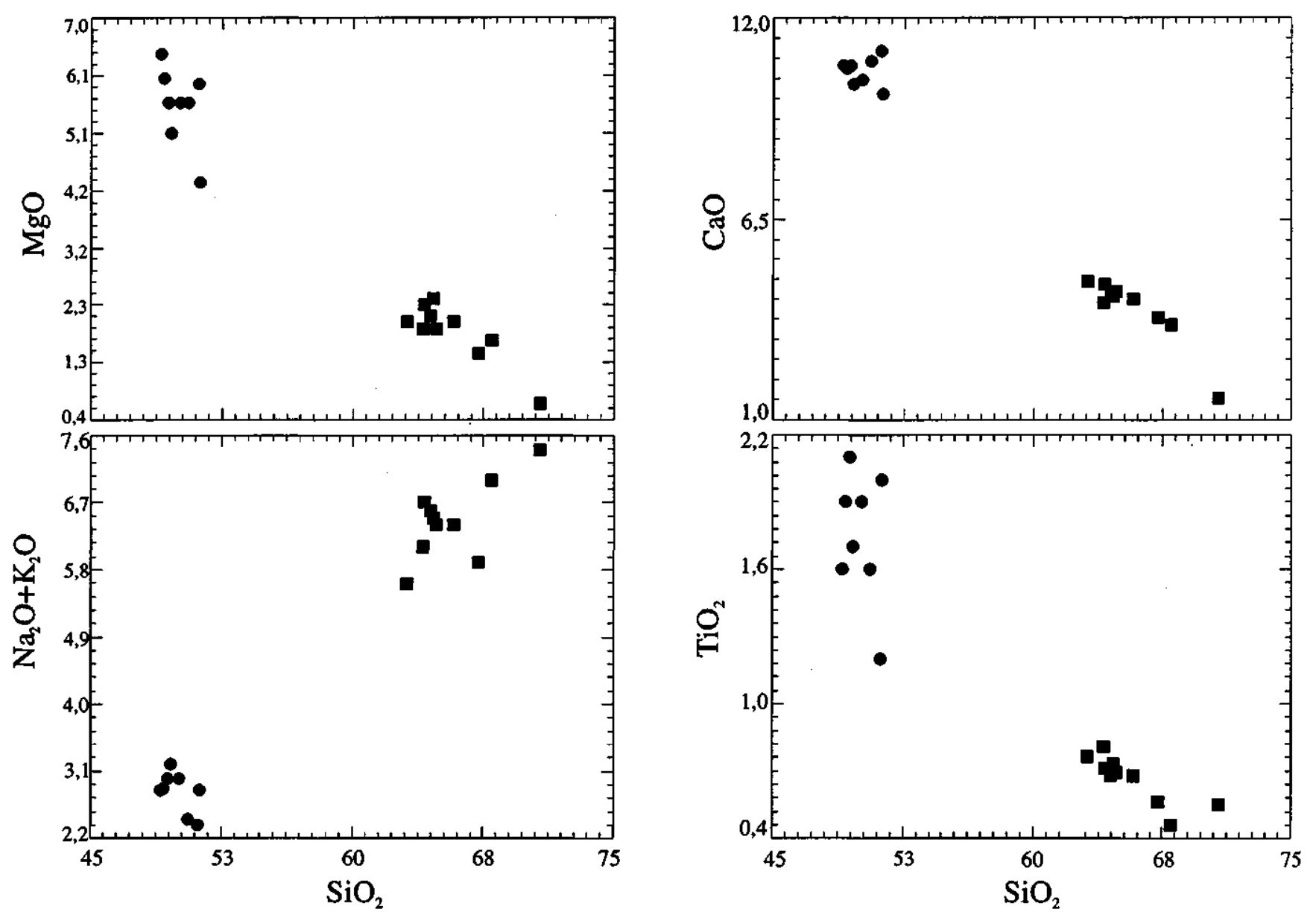

Figura 5 - Diagramas selecionados do tipo Harker onde se observam dois nítidos agrupamentos de resultados para o Tonalito Samambaia (quadrados) e o Anfibolito Candeias (círculos) e a ausência de termos intermediários entre estas duas suites Figure 5 - Selected Harker diagrams showing two distinct plot concentrations for the Samambaia Tonalite (boxes) and Candeias Amphibolite (circles) and the lack of intermediate types between these two rock suites

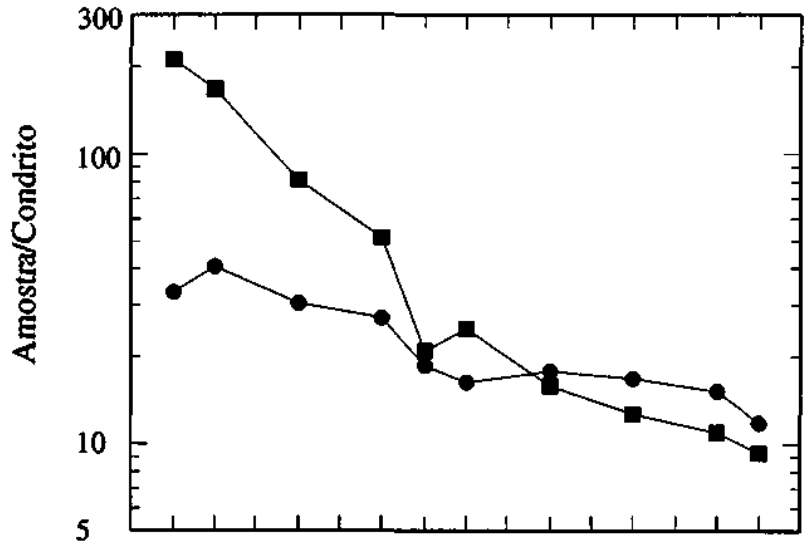

La Ce Pr Nd Pm Sm Be Gd Tb Dy Ho Er Tm Yb Li

Figura 6 - Diagrama de elementos de terras raras, normalizado para o condrito de Massuda et al (1973), mostrando os padrões geoquímicos do Tonalito Samambaia (quadrados) e do Anfibolito Candeias (círculos)

Figure 6 - Chondrite normalized (Massuda et al. 1973) REE pattern for the Samambaia Tonalite (boxes) and Candeias Amphibolite (circles)

tita ou homblenda do Tonalito Samambaia. Portanto, as máficas Candeias foram metamorfizadas de modo muito mais homogêneo do que o Tonalito Samambaia que elas cortam na forma de diques.
CONCLUSÕES Os resultados petrográficos e geoquímicos acerca do Tonalito Samambaia e do Anfibolito Candeias, discutidos acima, permitem concluir que estas duas suítes não apresentam termos petrográficos intermediários entre si, tratando-se, portanto, de duas suítes magmáticas distintas. $\mathrm{O}$ caráter não-cogenético destas duas suítes está, de certa forma, confirmado pelos dois agrupamentos distintos de idades Sm-Nd (TDM; Tabela 1). Enquanto o Tonalito Samambaia mostra idades Sm-Nd da ordem de 2940 e $2800 \mathrm{Ma}$, o Anfibolito Candeias tem uma idade da ordem de $2680 \mathrm{Ma}$ (Carneiro et al. 1995; Carneiro et al. 1996; Teixeira et al. 1996). O metamorfismo ocorrido no Anfibolito Candeias, situado no limite entre a fácies xisto verde alto a anfibolito baixo, foi um processo restrito em termos regionais, porém amplo e eficaz na transformação dos protólitos desta suíte. Este processo foi favorecido pela existência das zonas de fraqueza e pelos próprios planos de descontinuidade crustal por onde o magma tholeiítico, responsável pela geração dos protólitos do Anfibolito Candeias, ascendeu crosta acima. A concentração do fluxo de fluidos, nestes planos, favoreceu as transformações metamórficas no protólito do Anfibolito Candeias. No caso do Tonalito Samambaia esta transformação metamórfica foi dificultada, não só pela características texturais deste granitóide (tipicamente maciço), como também, pela ausência de descontinuidades estruturais por onde o fluxo de fluidos pudesse ter sido canalizado. Finalmente, fica claro que a atuação do Evento Transamazônico, no âmbito do Complexo Metamórfico Bonfim e, por conseguinte, no Quadrilátero Ferrífero, tem um caráter heterogêneo do ponto de 
vista de seu regime tectono-metamórfico. Por isto, é possível encontrar, no Complexo Metamórfico Bonfim, o registro de idades U-Pb arqueanas nas titanitas do Tonalito Samambaia, o que não acontece, por exemplo, em outros domínios da crosta siálica do Quadrilátero Ferrífero, onde titanitas de gnaisses arqueanos do Complexo Belo Horizonte (Figura 1) .forneceram idades U-Pb proterozóicas (Noce 1995).

Metodologia As análises químicas em rocha total foram realizadas no GEOLAB/Geosol com amostras em duplicata para o controle dos resultados analíticos. Os métodos empregados foram os seguintes: Fluorescência de Raios-X (por fusão da amostra com tetraborato de $\mathrm{Li}$ ) em Al, Ca, e $\mathrm{Fe}^{\text {(total) }}, \mathrm{Si}, \mathrm{Mg}, \mathrm{P}, \mathrm{Cr}$ e Ti; Fluorescência de Raios-X (pó prensado) em $\mathrm{Ba}, \mathrm{Cl}, \mathrm{Cs}, \mathrm{S}, \mathrm{Nb}, \mathrm{P}, \mathrm{Rb}, \mathrm{Sr}, \mathrm{Y}$ e Zr; Absorção Atômica em K, Mg, Mn, Na e Pb; Espectrografia Óptica em
$\mathrm{Zn}, \mathrm{Cu}, \mathrm{Co}, \mathrm{Sc}, \mathrm{Ni}$ e V; Titulação (com permanganato de K) em $\mathrm{Fe}^{2+}$; Espectrometria de Plasma nos elementos de terras raras (REE). Os erros estimados nestes procedimentos analíticos são da ordem de 1\% para Fluorescência de Raios-X (fusão); 5\% para Fluorescência de Raios X (pó prensado); 3\% para Absorção Atómica; 5\% para Espectrografia Óptica e Espectrometria de Plasma.

Agradecimentos Os autores agradecem às seguintes instituições pelo apoio financeiro e laboratorial: CNPq, FAPEMIG, CEPEGEO/USP, GEOTOP/UQAM/Montreal, CPQ/DEGEO/EM/UFOP, GEOLAB/GEOSOL. Agradecimentos especiais à Beatriz Baeta Mol (CEEL) e Rinaldo Afrânio Fernandes (Totó) pela editoração e confecção dos desenhos e, finalmente, aos dois revisores anônimos que muito contribuíram para clareza deste relato.

\section{REFERÊNCIAS}

ACKERMAND, D. \& KARL, F. - 1972 -Experimental studies on the formation of inclusions in plagioclases from metatonalites, Hohe Tauern, Austria (lower temperature stability limit of the paragenesis anorthite plus potash feldspar). Contrib. Mineral. Petrol., 35:11-21.

BRAUN, E. - 1974 -Mikrosondenuntersuchungen von Saussuriten in Abhàngigkeit vom Metamorphosegrad und vom geochemischen Milieu. Contr. Mineral. Petrol., 46:301-327.

CARNEIRO, M. A. -1992 -O Complexo Metamórfico Bonfim Setentrional (Quadrilátero Ferrifero, Minas Gerais): Litoestratigrafia e Evolução Geológica de um Segmento de Crosta Continental do Arqueano. São Paulo, 233p. (Tese de Doutoramento, Instituto de Geociências, Universidade de São Paulo).

CARNEIRO, M. A.; TEIXEIRA, W. - 1993 -Geoquímica e geocronologia dos diques máficos Precambrianos do Complexo Metamórfico Bonfim Setentrional, região meridional do Craton do São Francisco, Brasil. In: SEMANA DE GEOQUÍMICA, IX; CONGRESSO GEOQUÍMICO DOS PAISES DE LINGUA PORTUGUESA., II, Porto, 1993. Memórias... Porto, p. 15-16.

CARNEIRO, M. A.; JORDT-EVANGELISTA, H.; TEIXEIRA, W.; CUNHA, E. M. -1994 - Tonalito Arqueano com textura ígnea preservada nos terrenos granito-greenstone do Quadrilátero Ferrífero. In: CONGRESSO BRASILEIRO DE GEOLOGIA., 38, Camboriú, 1994 Boletim de Resumos Expandidos... Camboriú, SBG, 1:81-82.

CARNEIRO, M. A.; NOCE, C. M.; TEIXEIRA, W. - 1995 - Evolução po.icíclica do Quadrilátero Ferrífero: uma análise fundamentada no conhecimento atual da geocronologia U-Pb e geoquímica isotópica Sm-Nd. Rev. Escola de Minas, 48(3):264-273.

CARNEIRO, M. A.; TEIXEIRA, W.; NOCE, C. M.; FERNANDES, R. A. 1996 - Archean growth processes in the Quadrilátero Ferrífero: A geochronological $\mathrm{U}-\mathrm{Pb}$ and $\mathrm{Sm}-\mathrm{Nd}$ approach to the Rio das Velhas Event $(2780$ - $2700 \mathrm{Ma})$. In: Simpósio de Terrenos Arqueanos da Plataforma Sul-Americana. Brasília. 1996. Anais ... Brasília, SBG, p. 59 e 60.

CONDE, K. C. - 1981 - Archean greenstone belts. 1 ed. Amsterdam, Elsevier. $434 p$

COX, K. G.; BELL, J. D.; PANKHURST, R. J. -1979 - The interpretation of Igneous Rocks. 1 ed. London, George Allen \& Unwin, 450p.

DORR II, J. Van N. - 1969 - Physiographic, Stratigraphic and Structural Development of the Quadrilátero Ferrífero, Minas Gerais, Brazil. U.S G S. Professional Paper, 641(A). 110p.

GOLIA, A.; CARNEIRO M. A. OLIVEIRA, C. G. de -1996 - Meta-conglomerados da região de São Bartolomeu, Quadrilátero Ferrífero, Minas Gerais: Natureza, área fonte e implicações tectônicas. In: CONGRESSO BRASILEIRO DE GEOLOGIA., 39, Salvador, 1996. Anais... Salvador, SBG.
JORDT-EVANGELISTA, H., ALKMIM, F. F., MARSCHAK, S. - 1993a Transformaç̃es mineralógicas e microestruturais do Granito Mamona (Complexo Metamórfico Bonfim), na zona de cisalhamento do contato com o Supergrupo Minas, Quadrilátero Ferrífero, MG. In: SNET, IV, Belo Horizonte, 1993. Anais... Belo Horizonte, SBG, Núcleo MG, Boi. 12 , p. $246-250$.

JORDT-EVANGELISTA, H., CARNEIRO, M. A, LINDENBERG, S. F. 1993 b - Variações químicas do Granito Mamona (Complexo Metamórfico Bonfim), na zona de cisalhamento do contato com o Supergrupo Minas, Quadrilátero Ferrífero, MG. In: Simp. Geol. Minas Gerais, VII, Belo Horizonte. Anais... Belo Horizonte, SBG, Núcleo MG, Boi. 12, p. 108-111.

LADEIRA, E. A. -1985 - Metalogênese do Ouro na Mina de Morro Velho e no Distrito de Nova Lima, Quadrilátero Ferrífero, Minas Gerais, Brasil. In: Contribuicões à Geologia e à Petrologia. Belo Horizonte, CBMM. p. 95-151 (Núcleo de Minas Gerais, SBG, Boletim Especial).

MACHADO, N. \& CARNEIRO, M. A. - 1992 - U-Pb evidence of Late Archean tectonothermal activity in southern São Francisco shield, Brazil. Can. J. Earth Sciences, 29:2341-2346.

MASSUDA, A.; NAKAMURA, N.; TANAKA, T. -1973 - Fine structures of mutually normalized rare-earth pattern of chondrites. Geochim. Cosmochim. Acta, 36:379-382.

NOCE, C. M. -1995 - Geocronologia dos eventos magmáticos, sedimentares e metamórficos na região do Quadrilátero Ferrífero, Minas Gerais. São Paulo, 128p. (Tese de Doutoramento, Instituto de Geociências, Universidade de São Paulo).

RUMBLE, D. - 1989 - Evidences of fluid flow during regional metamorphism. Eur. J. Mineral, 1:731-737.

SCHORSCHER, H. D.; SANTANA, F. C.; POLÓNIA, J.C. \& MOREIRA, J. M. P. - 1982 - Quadrilátero Ferrífero -Minas Gerais State: Rio das Velhas Greenstone Belt and Proterozoic Rocks. In:-International Symposium on Archean and Early Proterozoic Evolution and Metallogenesis, Salvador, 1982. Excursion Annex... Salvador, SBG. 43p.

TEIXEIRA, W.; CARNEIRO, M. A.; NOCE, C. M.; MACHADO, N.; S ATO; TAYLOR, P. N. $-1996-\mathrm{Pb}, \mathrm{Sr}$ and $\mathrm{Nd}$ isotope constraints on the Archean evolution of gneissic-granitoid complexes in the southern São Francisco Craton, Brasil. Precambrian Res., 78:151-164.

Manuscrito A886

Recebido em 15 de novembro de 1996

Revisão dos autores em 15 de abril de 1997

Revisão aceita em 15 de junho de 1997 